\title{
CAN EMERGENCY REMOTE EDUCATION MAKE UNIVERSITIES “SMARTER"? LECTURERS' REFLECTIONS ABOUT USEFUL LITERACIES
}

Antonella Giacosa, Department of Foreign Languages, Literatures and Modern Cultures, Italy

\section{Abstract}

The shift of the entire education system onto digital platforms due to the coronavirus emergency has made lecturers and students massively experience digital teaching and learning, its challenges and possibilities. As with another possible lockdown looming on the new academic year Emergency response education (ERE) might have to be turned into the new normal of distance learning, the wisdom learned by the massive online experience of the last semester could contribute to planning a nimble response to educational needs in case universities have to shift online again.

This paper aims at contributing to the discussion on key literacies lecturers might find useful to turn ERE into quality distance education. 24 full professors of English and English linguistics courses from 14 Italian universities have filled in an online questionnaire investigating the challenges and opportunities they have experienced during the emergency which shed light on the multiple literacies they should focus on to plan an effective response to a new emergency, which at the same time could make high school education "smarter" both inperson and online.

Keywords: Emergency Remote Education; Higher education; Multiple Literacies

\section{Introduction}

These are not normal times. As the historian Harari pointed out, the coronavirus outbreak has forced governments, businesses, and educational boards to carry out large scale experiments they would never have agreed to conduct in normal times (Harari, 2020). In an attempt to curb the spread of the virus, the Italian government officially declared Italy's lockdown in late February 2020. Among other things, this forced the entire education system to suddenly shift onto digital platforms that only a few teachers and students were 
Giacosa, A.

Can Emergency Remote Education Make Universities “Smarter"? Lecturers' Reflections about Useful Literacies

familiar with; face-to-face courses had to be turned into distance learning in a very short time.

However, an unprecedented challenge can be turned into an opportunity. After a second semester taught entirely remotely and exams performed digitally, the strengths and weaknesses of the academic response to the emergency can be identified. As almost all students and lecturers have experienced online learning and teaching first-hand, they are now able to have informed opinions about the challenges and strategies involved and can provide suggestions to improve the online academic experience. With the spectre of another possible lockdown looming on the new academic year, Emergency Response Education (ERE) might have to be turned into "the new normal" of distance learning. In this context, the wisdom gained by the massive online experience of the last semester can contribute to planning a nimble response to educational needs in case universities have to shift online again.

This paper presents several critical points concerning key literacies lecturers may need in order to transform ERE into quality distance education: the perceptions and reflections of 24 lecturers from 14 Italian universities are presented and discussed in terms of the new challenges universities have to face under these circumstances. Moreover, it sheds light on issues of concern which could make education "smarter" and more inclusive. First, this study will be situated within the existing literature and its novelty will be highlighted; second, the research questions and the methodology used to gather data will be presented; third, data will be examined to identify trends emerging from lecturers' perceptions and reflections on their ERE experience; finally, specific literacies will be highlighted which may enable us to turn emergency remote education into a smarter, high quality "new normal" in higher education.

\section{Literature review and the state of the art}

Until February 2020, e-learning was regarded as a subsidiary tool, a useful helper, a dangerous competitor, a threat to human resources and academic quality, a cheap and profitable marketing booster or a licence for diploma mills. Due to the massive migration of education onto digital platforms, there has been increasing attention to Emergency Response Education (ERE), a branch of distance learning which deals with the unplanned educational response to a crisis. While online or distance education is an option which relies on planning, theoretical and practical knowledge, and consolidated models (Siemens, 2005; Gaebel et al., 2014, Gaebel \& Zhang, 2018; Yuwono \& Sujono, 2018; Ossiannilsson et al., 2015), ERE is a necessary change in response to an emergency (Bozkurt et al., 2020). Before the Covid19 outbreak, emergency or crisis education had concerned itself with the psychological stabilising of children and young people in warfare 
Giacosa, A.

Can Emergency Remote Education Make Universities “Smarter"? Lecturers' Reflections about Useful Literacies

and the aftermath of natural catastrophes mostly in Africa, the Middle East and the Far East (Ruf, 2013; UNESCO, 2020). During the emergency caused by Hurricane Katrina in 2005, for example, American universities mainly focused on the psychological and concrete help of offering housing and facilities (Gill et al., 2006). The current emergency due to Covid 19 is different from the previous ones because, as a pandemic, it has affected nearly every nation on earth, including wealthy western countries on a massive scale (not only in well-defined limited areas) (Harari, 2020; Lau \& Ross, 2020). So, dealing with ERE from the lecturers' perspective this paper aims at contributing to address a loophole in the scientific literature: as it is an unprecedented phenomenon in western countries, scholars have not yet carried out in-depth studies to analyse what happens when a course planned as face-to-face has to become an online experience, and what changes must be made to turn ERE into quality distance teaching.

\section{Research questions and methodology}

The main goal of this paper is to investigate how lecturers perceive and assess the academic digital response to challenges posed by the sudden shift from face-to-face to online classes during the academic year 2019/2020 in order to shed light on key aspects universities should focus on to turn emergency remote pedagogy into quality online teaching and learning. It aims to answer the following research questions:

- RQ1: What are the key factors that could turn ERE response into quality digital courses?

- RQ2: What literacies and soft skills do lecturers need in order to support students and guarantee quality distance learning?

These research questions are part of a wider study focusing on the academic response to the coronavirus emergency in Italian universities concerning English Language and English Linguistics courses in Foreign Languages and Economics degree programmes. The main findings are based on the answers of 24 lecturers to an online questionnaire. Universities were chosen randomly and lecturers were contacted via email. Those who participated in the project allowed the researcher to observe 3 live online classes attended by the same group of students and filled in an anonymous online questionnaire which could be completed in approximately 20 minutes. The questionnaire was composed of closed questions, open-ended questions and Likert-scale-based questions. Its three sections aimed at investigating the participants' digital skills, their teaching experience before and during the outbreak and the difficulties encountered, and best practices suggestions for possible future emergencies. Data was gathered from March to July 2020 and was analysed with a quantitative and qualitative approach: quantitative data referring to lecturers' 
Giacosa, A.

Can Emergency Remote Education Make Universities “Smarter"? Lecturers' Reflections about Useful Literacies

answers to closed-ended questions are integrated with their open comments, which help give a deeper insight into their experience and perceptions.

\section{Main findings}

The following section introduces critical aspects of universities' digital response to the Covid-19 emergency. Two main areas of concern emerged: professional issues, in terms of digital literacy and perceptions of self-efficacy; and emotional issues for both teachers and students, due to the particularly stressful environment caused by the move online.

\section{Professional aspects: Digital teaching literacy and perception of self-efficacy}

By and large, universities offered a quick educational response which allowed students to carry on with their studies during the crisis. Lecturers taught live classes online, recorded online lessons for asynchronous access, pre-recorded video lessons and had online office hours. The survey of lecturers yielded the following results: $50 \%$ of the respondents considered their live classes very useful, $41 \%$ considered them fairly useful; in terms of the content delivered, $52 \%$ were very satisfied and $30 \%$ were fairly satisfied. $35 \%$ of the lecturers think their live classes were better than face-to-face classes; in fact, they reported more students attended and were more active and asked more questions. However, $44 \%$ of the respondents still prefer in-person courses.

Even though $96 \%$ of the lecturers experienced some difficulties with technology, overall the lecturers now feel more familiar with technology after the coronavirus emergency, as shown in the table below. If compared to their perceptions before the emergency, the number of lecturers who felt not familiar at all or just somewhat familiar with educational technologies has decreased, whereas the number of the respondents who felt fairly familiar and extremely familiar has sensibly increased.

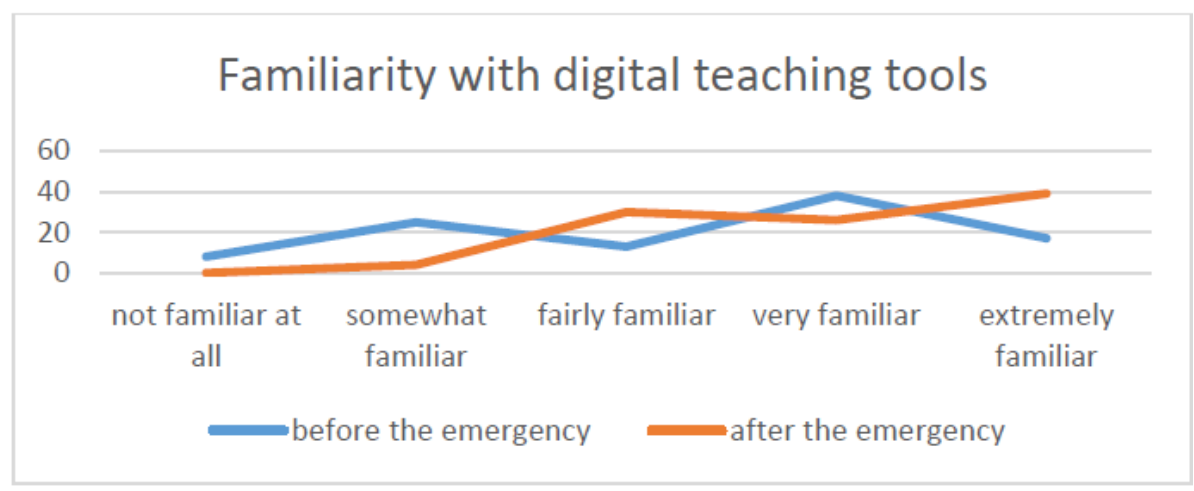

Figure 1. Familiarity with digital tools before and after the emergency

Despite a general feeling of satisfaction, in hindsight some of them would change the way they organized their lessons: they would like to find new ways to introduce content and implement students' interaction and involvement. Lecturers highlight the need for more 
Giacosa, A.

Can Emergency Remote Education Make Universities “Smarter"? Lecturers' Reflections about Useful Literacies

technical support and training to make the most of the digital tools and platforms: some platforms allowed students be more interactive (by providing breakout rooms to work in smaller groups) while others did not, and lecturers would like to have a broader and deeper understanding of different tools in order to be able to answer their students' needs better. In adapting to the new context, $96 \%$ experienced some difficulties, which they faced with different strategies and all-round commitment: 58\% explored technology on their own, $21 \%$ watched tutorials online, 54\% asked their colleagues for advice, 37\% contacted the elearning centre of their university for help, 33\% were helped by friends or family members; finally, $17 \%$ found it necessary to improve their internet connection and $8 \%$ decided to buy a new device which could support the required technology.

Even though 35\% of the respondents reported they did not feel sufficiently familiar with digital educational tools, only $9 \%$ were dissatisfied with their outcomes. The time commitment was an important concern: most found preparing video lessons very timeconsuming (75\%), many spent time developing new ways of teaching (44\%), reorganising their course schedule and slides (34\%) and arranging extra lessons to help students who were struggling (18\%). In terms of assessment, only $13 \%$ of the respondents declared they did not change anything about their exams; instead, 35\% organised mock exams because of the unusual circumstances, $40 \%$ had to change or simplify the exam, $17 \%$ had to change the type of questions and tasks, and $17 \%$ opted for an oral exam to prevent cheating. Despite the technical challenges of the almost overnight shift of education onto digital platforms, lecturers have managed to accomplish their tasks; however, it may have taken a toll on them, as discussed in the next section.

\section{Emotional aspects: digital stress and emotional commitment}

In the unprecedented situation caused by the coronavirus emergency, lecturers have had to face additional responsibilities which have made their emotional commitment more intense than usual. On the one hand, lecturers had to put in place different resources to cope with ERE and feel they should get more support and better working conditions in case of new emergencies: $90 \%$ of the respondents highlighted the need to do more to help all lecturers, but particularly those lecturers who are not familiar with technology; more specifically, they identified the need for more training not only to improve their teaching but also to reduce the concomitant anxiety. Citing the difficulties they experienced, $50 \%$ of them felt anxious about online live classes and 50\% missed human interaction, $48 \%$ were worried about wi-fi connection problems, 39\% said it was difficult to carry on with the lessons, 35\% felt as if they were talking into the void, $22 \%$ were afraid of not being able to help students. 
Giacosa, A.

Can Emergency Remote Education Make Universities “Smarter"? Lecturers' Reflections about Useful Literacies

On the other hand, respondents reported having to be more aware of their students' emotional needs as well: lecturers tried to accommodate their students' wi-fi connection problems (87\%), the lack of study material (48\%) and elevated anxiety about exams (48\%). To support their students' well-being, lecturers not only organised extra lessons and office hours to listen to their students, clarify doubts and answer questions, but they employed new tools such as digital breakout rooms to increase students' interaction with their peers.

Table 1: Main issues concerning emotional aspects related to ERE in lecturers' perception (more than one answer was allowed)

\begin{tabular}{lc}
\hline How did you feel during online live classes? & $\%$ \\
\hline I felt anxious about online live classes & $50 \%$ \\
I missed human interaction & $50 \%$ \\
I was afraid of connection problems & $48 \%$ \\
It was difficult to carry on with the lessons & $39 \%$ \\
I felt as if I was talking into the void & $35 \%$ \\
I was afraid not being able to help students & $22 \%$ \\
\hline
\end{tabular}

\section{Comments and suggestions}

As the data described above shows, the sudden shift to ERE has challenged lecturers from both professional and emotional points of view. Even if the respondents were satisfied with their experience of ERE as reported in the previous paragraphs, they emphasized the need for more training and support: to cope with new emergencies and turn their ERE response into quality distance learning, they need to focus on multiple literacies.

\section{Effective digital teaching through multiple literacies}

The respondents experienced new ways of teaching and increased their usual support to students, but they seemed aware of the need for more training to cope with the multiple challenges of remote learning and teaching. ERE has shown that "online learning is not just a matter of using a digital platform to teach the same class that would have been otherwise taught in a physical setting". They emphasized the fact that the preparation of online classes is time-consuming, as online learning requires a deep restructuring of the teaching approach and the use of different digital tools to satisfy different educational needs (Frattini, 2020). In order to move forward efficiently, therefore, lecturer training in the current context should include the following: digital literacy, workload literacy, openness and sharing literacy, well-being and care literacy, and socio-emotional literacy, as detailed below.

The respondents pointed out that they could not rely on their students' usual feedback: lecturers found it more difficult to "read the digital room" and get feedback, which during an in-person class could be provided by their students' facial expressions, their whispering 
Giacosa, A.

Can Emergency Remote Education Make Universities “Smarter"? Lecturers' Reflections about Useful Literacies

or their questions. Even if respondents expressed a very positive opinion of their ERE experience, they missed the repartee which in the past had helped them to make their lessons livelier and to identify students' needs and respond to them. In response to this lack of in-person interaction, some respondents recorded their online classes to help students who had not attended them; others recorded video lessons students could watch as many times as they liked and answered their questions during their office hours. Others organised digital competitions to help their students to consolidate content and be more involved; still others used breakout rooms to make students interact more. All in all, lecturers proved to be very resourceful, but they feel they would benefit from specific training to improve their digital literacy to master the various options smart platforms provide and to offer students different paths and to enrich the activities to meet different students' needs and learning styles.

Lecturers also found it challenging to plan students' workload, since in addition to the level of difficulty of the content and number of pages, they also have to take into account what else students might be dealing with, such as stressful events or unexpected difficulties, which is often the case during an emergency (Bali, 2020). So, lecturers could benefit from training on workload literacy in order to tailor the tasks according to their students' needs under those unusual circumstances. More specifically, assessment seems to have been an issue of major concern during the pandemic. As data shows, lecturers needed to change their usual exam format to fit the content and the activities they had managed to include during classes and to prevent cheating; it was more time-consuming than usual and an additional burden to think and plan new exam formats, have oral exams instead of written ones, respond to the emails of anxious students who needed to have more information about the new exams, etc.

During an emergency, libraries may be closed and both students and lecturers may find it difficult to access material related to the courses and exams, as was the case during the covid19 pandemic. As data shows, lecturers were aware of the fact that many students were not able to access materials from their libraries or in some cases, their books. Consequently, they needed to help students, but they had to do so without infringing on copyright laws: as many of their students did not have their books and study material with them during the lockdown, lecturers had to sometimes create and upload more materials onto their university pages, which increased their workload. It appears that openness and sharing literacy should be included in lecturers' training: mastering OER (open education resources) and sharing them with students and with colleagues can help relieve the burden and free up mental space to tackle other issues, such as their own or their students' emotional needs. 
Giacosa, A.

Can Emergency Remote Education Make Universities “Smarter"? Lecturers' Reflections about Useful Literacies

As the data shows, lecturers were put under pressure from various sources during the coronavirus emergency: on the one hand, they had to face increased workloads professionally in addition to their family duties, which also may have increased while their children stayed home from school; on the other hand, they had to meet students' increased emotional needs and help relieve their anxieties. As carers need to take care of both themselves and their students, even more during an emergency, it appears that well-being and care literacy along with socio-emotional literacy should be part of specific training. As was shown in the previous paragraph, the respondents reached out to their colleagues, family members, friends, and the e-learning experts from their universities to face technological difficulties; according to their comments, this was helpful. So being aware of one's own emotional needs and relying on competent help and support can help lecturers to rise to the challenge of the additional tasks due to an emergency, such as being ready to face their students' anxiety and additional needs. Moreover, the physical distancing established to curb the spread of the virus made classes the only social spaces students could benefit from. Consequently, in addition to showing understanding to their students and providing help and support, they had to organize chats, reply to students' emails, establish office hours to answer questions and semi-formal spaces for semi-synchronous communication.

To sum up, being aware of the complexities of quality distance teaching and being trained to tackle the major issues appears to be the best way to guarantee a nimble response to new emergencies and to make higher education "smarter" in non-emergency situations as well. Further research is needed to meet lecturers' needs in terms of training: they have shed light on key elements and questions have arisen, which need to be answered by further and more specific investigation.

\section{Conclusions}

Our contemporary society is the most technologically advanced in human history and, in most places, good digital skills and access to technology are taken for granted. However, the coronavirus emergency has shown that the sudden and unplanned shift of education onto digital platforms can be critical from different points of view. To respond effectively and live up to their role, lecturers need to master multiple literacies involving professional and emotional aspects and need specific training and support. As an added benefit the renewed attention to useful literacies for lecturers could lead to a general improvement and implementation of higher education, but further research is needed to provide professionals with the necessary tools and knowledge.

In conclusion, will ERE make education smarter? Apart from helping lecturers and students to accomplish their tasks, ERE has shown key aspects to address. Lecturers' have 
Giacosa, A.

Can Emergency Remote Education Make Universities “Smarter"? Lecturers' Reflections about Useful Literacies

shown positive commitment, and this brightens the outlook for the forthcoming academic year, over which a potential new wave of the virus is looming. Now it is up to faculties to prioritise. ERE might makes University smarter in the long run, but faculties should put the necessary resources in place to respond to its call to action.

\section{References}

Bali, M. (2020, May 13). Literacies Teachers Need During Covid-19. Al-FanarMedia [Blog post]. https://www.alfanarmedia.org/2020/05/literacies-teachers-need-during-covid$19 /$

Bozkurt, A., Xiao, F., Jung, I., \& Vladimirshi, V. (2020). A global outlook to the interruption of education due to COVID-19 Pandemic: Navigating in a time of uncertainty and crisis. Asian Journal of Distance Education, 15(1).

Frattini, F. (2020, March 26). Smart Learning in Times of Coronavirus Emergency... and beyond. Retrieved from https://www.som.polimi.it/en/smart-learning-in-times-ofcoronavirus-emergency/

Gaebel, M., Kupriyanova, V., Morais, R., \& Colucci, E. (2014). E-learning in European Higher Education Institutions. Results of a mapping survey conducted in OctoberDecember 2013. Brussels: European University Association Retrieved from http://www.eua.eu/Libraries/publication/e-learning_survey.pdf?sfvrsn=2

Gaebel, M., \& Zhang, T. (2018). Trends 2018. Learning and Teaching in the European Higher Education Area. Brussels: European University Association. Retrieved from https://eua.eu/resources/publications/757:trends-2018-learningand-teaching-in-theeuropean-higher-education-area.html

Gill, D. A., Mcseveney, D. R., \& Ladd, A. E. (2006). Impacts of Hurricane Katrina on Mississippi State University Students. In Natural Hazard Centre (Ed.), Learning from Catastrophe, Quick Response research in the wake of Hurricane Katrina (pp. 373-402). Boulder C.O.

Harari, Y. N. (2020, March 20). Yuval Noah Harari: the World after Coronavirus. Financial Times [Blog post]. Retrieved from https://www.ft.com/content/19d903086858-11ea-a3c9-1fe6fedcca75

Lau, J., \& Ross, J. (2020, February 17). Universities Brace for Lasting Impact of Coronavirus Outbreak. Times Higher Education [Blog post]. Retrieved from https://www.timeshighereducation.com/news/universities-brace-lasting-impactcoronavirus-outbreak 
Giacosa, A.

Can Emergency Remote Education Make Universities “Smarter"? Lecturers' Reflections about Useful Literacies

Natural Hazard centre American Association of University Professors (AAUP). (2007). Hurricane Katrina and New Orleans Universities, Report of an AAUP Special Committee. Retrieved from https://portfolio.du.edu/downloadItem/92556

Ossiannilsson, E., Williams, K., Camilleri, A., \& Brown, M. (2015). Quality Models in Online and Open Education around the Globe. State of the Art and Recommendations. Oslo: International Council for Open and Distance Education.

Ruf, B. (2013). Educating Traumatized Children: Waldorf Education in Crisis Intervention. Lindisfarne Books. Great Barrington, Ma: Steiner Books/ Anthroposophic Press Inc.

Siemens, G. (2005). Connectivism: A Learning Theory for the Digital Age. International Journal of Instructional Technology and Distance Learning, 2(1), 1-6.

UNESCO. (2020). From Subregional to a Continental Response Strategy in Support of more Resilient and Responsive Education Systems in Africa Covid-19 (C-19), April- June 2020. Regional Office for Eastern Africa. Retrieved from https://en.unesco.org/themes/education-emergencies

Yuwono, K. T., \& Sujono, H. D. (2018). The Effectiveness of E-Learning: A Meta-Analysis. IOP Conf. Series: Journal of Physics: Conf. Series, 1140. 